\title{
Review on the Alteration of Gut Microbiota: The Role of HIV Infection and Old Age
}

\author{
Akililu Alemu Ashuro,, Tekle Airgecho Lobie, ${ }^{2}$ Dong-Qing Ye,, Rui-Xue Leng,, \\ Bao-Zhu Li, ${ }^{1}$ Hai-Feng Pan, ${ }^{1,3}$ and Yin-Guang Fan ${ }^{1}$
}

\begin{abstract}
Human immunodeficiency virus (HIV) infection results in gut microbiota alteration and this is associated with immune activation and chronic inflammation. The gastrointestinal tract is a primary site of viral replication and thus HIV-induced loss of T-helper (Th) cells in the gut causes impairments in intestinal barriers, resulting in disruptions in intestinal immunity and precipitating into gut dysbiosis. Here, we show that late HIV diagnosis can negatively affect the immunological, virological, and clinical prognosis of the patients with its higher implication at an older age. Further, the review indicates that antiretroviral therapy affects the gut microbiota. We discussed the use of probiotics and prebiotics that have been indicated to play a promising role in reversing gut microbiota alteration in HIV patients. Though there are several studies reported with regard to such alterations in gut microbiota regarding HIV infection, there is a need to provide comprehensive updates. It is, therefore, the objective of this review to present most recently available evidence on the alteration of gut microbiota among HIV patients.
\end{abstract}

Keywords: HIV/AIDS, gut microbiota, late diagnosis, old age, ART, probiotics/prebiotics

\section{Introduction}

M ORE THAN 36.9 MILLION (31.1-43.9) people were living with human immunodeficiency virus, and there were 1.8 million new cases and 940,000 deaths from acquired immunodeficiency syndromes (AIDS)-related causes reported by Joint United Nations Program on HIV/AIDS (UNAIDS) in 2017. The same report indicated a declined incidence rate from 3.4 million in 1996 to 1.8 million in 2017. ${ }^{1}$ Human immunodeficiency virus (HIV) is a virus that causes AIDS; an advanced stage of its infection is characterized by a rapid and substantial cluster of differentiation (CD) $4^{+} \mathrm{T}$ cell depletion, and chronic immune system activation with indications to have a strong association with the gastrointestinal tract (GIT). ${ }^{2,3}$ Thus, GIT is a prominent site of viral replication and a complex community for more than 100 trillion microbial cells, which are major regulators of the immune system that potentially influence human physiology, metabolism, nutrition, and immune function. ${ }^{4-7}$ As such, HIV-1 infection has been implicated in reducing gut microbiota diversity and enhancing microbial translocation. ${ }^{8}$ Therefore, here we reviewed recent scientific articles focusing on different characteristics shown in Table 1, and they are presented in a detailed discussion next.

\section{Alteration of gut microbiota among HIV patients}

Human GIT is a crucial regulator of T cell homeostasis and is intricately involved in the maturation of the immune system and maintaining the mutual co-existence of host and microbe. ${ }^{9}$ However, changes in their diversity and population were associated with $\mathrm{CD}^{+} \mathrm{T}$ cell counts and immune activation in HIV patients. ${ }^{10,11} \mathrm{Lu}$ et al. investigated the association between microbiota and $\mathrm{CD}^{+} \mathrm{T}$ cells recovery in HIV patients, and they showed the relative abundance of Faecalibacterium prausnitzii and Subdoligranulum spp. to have a connection with $\mathrm{CD} 4^{+} \mathrm{T}$ cell counts as evident by persistent depletion of $\mathrm{CD}^{+} \mathrm{T}$ cells with subsequent immune unresponsiveness. $^{11}$

In HIV patients, the viral level has an impact on the gut microbiota dysbiosis ${ }^{3}$ as suggested during acute and early HIV infection, when there was a $\mathrm{CD} 4^{+}$selective depletion of $\mathrm{T}$ cells in the distal GIT with its mucosa serving as a site of active HIV replication. ${ }^{12}$ Further, a study on the effects of HIV viremia on the gastrointestinal microbiome of young homosexual men identified variations in the microbial composition depending on the level of viremia. It was indicated that low levels of viremia (HIV RNA $<200$ copies/mL) had distinct microbial signatures from those who were HIV

\footnotetext{
${ }^{1}$ Department of Epidemiology and Biostatistics, School of Public Health, Anhui Medical University, Hefei, China.

${ }^{2}$ Department of Microbiology, Oslo University Hospital, Rikshospitalet and University of Oslo, Oslo, Norway.

${ }^{3}$ Inflammation and Immune Mediated Diseases Laboratory of Anhui Province, Hefei, Anhui, China.
} 
Table 1. General Characteristics of Included Studies in Gut Microbiota Alteration Among HiV Patients

\begin{tabular}{|c|c|c|c|c|c|}
\hline Author ${ }^{\mathrm{ref}}$ & Study design & Year & Country & Sample size & $\begin{array}{c}\text { Age of participant } \\
\text { (year) }\end{array}$ \\
\hline Cook et $a .^{3}$ & Prospective cohort & 2019 & Spain & $\begin{array}{l}200 \text { HIV - } 66 \text { (HIV RNA }<20 \\
\text { copies/mL) } \\
72 \text { (HIV RNA } \leq 200 \text { copies } / m L) \\
45 \text { (HIV RNA }>200 \text { copies/mL) }\end{array}$ & $\begin{array}{l}28.91(6.43)^{\mathrm{a}} \\
33.41(6.55)^{\mathrm{a}} \\
34.1(6.36)^{\mathrm{a}} \\
33.18(6.86)^{\mathrm{a}}\end{array}$ \\
\hline $\begin{array}{l}\text { Villar-Garcia } \\
\quad \text { et al. }\end{array}$ & Double blinded & 2017 & Spain & $\begin{array}{l}22 \operatorname{IR}\left(>400 \mathrm{CD}^{+}\right) \\
22 \operatorname{INR}\left(<270 \mathrm{CD}^{+}\right)\end{array}$ & $\begin{array}{l}44(37-49)^{\mathrm{b}} \\
52(47-57)^{\mathrm{b}}\end{array}$ \\
\hline Lu Et al. ${ }^{11}$ & Cross-sectional & 2018 & China Peking & $\begin{array}{l}60 \mathrm{HIV}+(4 \text { groups) } \\
26 \mathrm{VU} \\
15 \mathrm{IR} \\
20 \mathrm{INR} \\
30 \mathrm{HC}\end{array}$ & $\begin{array}{l}33.0(27.3-39.0)^{\mathrm{c}} \\
31.0(26.0-34.5)^{\mathrm{c}} \\
37.5(34.0-44.3)^{\mathrm{c}} \\
29.5(24.0-45.8)^{\mathrm{c}}\end{array}$ \\
\hline Dinh et al. ${ }^{14}$ & Exploratory study & 2015 & $\begin{array}{l}\text { United States, } \\
\text { Boston }\end{array}$ & $\begin{array}{l}21 \mathrm{HIV+} \\
16 \mathrm{HC}\end{array}$ & $\begin{array}{r}50.5(45.5-54.5)^{\mathrm{c}} \\
45(34.4-50.3)^{\mathrm{c}}\end{array}$ \\
\hline $\begin{array}{l}\text { Machiavelli } \\
\quad \text { et al. }\end{array}$ & Cross-sectional & 2019 & Brazil & $\begin{array}{l}7 \mathrm{HC} \\
12 \mathrm{HIV}+\end{array}$ & $\begin{array}{l}29(27-33)^{\mathrm{c}} \\
34(24-35)^{\mathrm{c}}\end{array}$ \\
\hline Liu et $a l^{21}$ & Cross-sectional & 2019 & $\begin{array}{c}\text { United States, } \\
\text { Colorado }\end{array}$ & $\begin{array}{l}14 \mathrm{HIV}+ \\
22 \mathrm{HC}\end{array}$ & $\begin{array}{l}61.5(13.5)^{\mathrm{c}} \\
58(8.8)^{\mathrm{c}}\end{array}$ \\
\hline Ling et $a l^{26}$ & $\begin{array}{l}\text { Cross-sectional } \\
\text { cohort }\end{array}$ & 2016 & China & $\begin{array}{l}67 \text { HIV+ } \\
32 \text { Treated } \\
35 \text { VU } \\
16 \text { HC }\end{array}$ & $\begin{array}{l}36.34 \pm 8.10^{\mathrm{a}} \\
36.63 \pm 8.05^{\mathrm{a}} \\
35.7 \pm 10.23^{\mathrm{a}}\end{array}$ \\
\hline Lee et $a l .{ }^{28}$ & Cross-sectional & 2018 & $\begin{array}{l}\text { Kuala Lumpur, } \\
\text { Malaysia }\end{array}$ & $\begin{array}{l}\text { HIV }+26 \\
\text { oIR } 16 \\
\text { sIR } 10 \\
\text { HC }\end{array}$ & $\begin{array}{l}40(34-45)^{\mathrm{c}} \\
49(41-52)^{\mathrm{c}} \\
31(28-46)^{\mathrm{c}}\end{array}$ \\
\hline Dillon et $a .^{32}$ & Cross-sectional & 2017 & $\begin{array}{c}\text { United States, } \\
\text { Colorado }\end{array}$ & $\begin{array}{l}18 \mathrm{HIV+} \\
14 \mathrm{HC}\end{array}$ & $\begin{array}{r}32.5(22-58)^{\mathrm{c}} \\
31(23-54)^{\mathrm{c}}\end{array}$ \\
\hline Rhoades et al. ${ }^{33}$ & Cohort & 2019 & $\begin{array}{l}\text { California, United } \\
\text { States }\end{array}$ & $\begin{array}{l}\text { HIV }+58 \\
\text { HIV }-47 \\
\text { HC } 20\end{array}$ & $\begin{array}{l}65.7(7.3)^{\mathrm{b}} \\
62.7(6.03)^{\mathrm{b}} \\
62.7(6.03)^{\mathrm{b}}\end{array}$ \\
\hline
\end{tabular}

Values are shown as ${ }^{\mathrm{a}}$ mean (SD), ${ }^{\mathrm{b}} \mathrm{SD},{ }^{\mathrm{c}}$ median (IQR) for age.

$\mathrm{BPB}$, butyrate-producing bacteria; $\mathrm{CD}$, cluster of differentiation; HC, healthy control; HIV, human immunodeficiency virus; INR, immune nonrespondent; IQR, interquartile range; IR, immune respondent; oIR, optimal immune responder; RA, relative abundance; SD, standard deviation; sIR, suboptimal immune responder; VU, untreated.

patients, but there was an undetectable viral load (HIV RNA $<20$ copies/mL). However, those with low-level viremia can still have microbial translocation and inflammation. In this group, depletions in Brachyspira, Campylobacter, and Parasutterella were noticed. However, HIV viral load-suppressed participants (HIV RNA $\leq 200$ copies/mL) had depletions in Barnesiella, Helicobacter, and Brachyspira relative to HIVnegative subjects. ${ }^{3}$

It is, therefore, not surprising that different patterns emerge when considering gut microbiota of HIV patients and healthy controls. Recently, a cohort study on the diversity of gut microbiota between HIV patients and healthy controls demonstrated that HIV patients have a significant decrease in Clostridia class and an increase in Gammaproteobacteria class. ${ }^{13}$ Lu et al. also investigated the changes in mucosal microbial composition and reported more Prevotella and fewer Bacteroides in HIV patients. ${ }^{11}$ In addition, during the bacterial profile from fecal microbiota by pyrosequencing the gene encoding $16 \mathrm{~S}$ ribosomal ribonucleic acid (16S rRNA) in 21 of chronic HIV patients and 16 seronegative individuals, the relative abundance of Gammaproteobacteria, Enterobacteriales, and Enterobacteriaceae in the Proteobacteria phylum; Erysipelotrichi, Erysipelotrichales, and Erysipelotrichaceae in the Firmicutes phylum was significantly enriched in cases, whereas that of Alistipes and Rikenellaceae was depleted. ${ }^{14}$

A difference has been also observed in the operational taxonomic unit abundance between healthy controls and HIV patients, with the most abundant families showing Ruminococcaceae and Prevotellaceae in healthy controls and HIV patients, respectively. An increased proportion of Preovtella copri (the most prevalent Prevotella species in the human gut 
associated with diet and disease) in HIV patients could indicate a dysbiosis of the microbiota. ${ }^{15}$

On the other hand, gut microbiota and/or age-related microbial changes were linked to an increased gut permeability with age that results in age-associated inflammation. ${ }^{16,17}$ Thus, an increase in the permeability of the intestinal mucosa, which could allow bacteria, bacterial toxins, and small molecules to leak into the bloodstream, ${ }^{18}$ is considered a major driving force of chronic immune activation. $^{19}$ In late-treated HIV patients, the intestinal permeability pointed toward increased absorption of highmolecular-weight molecules. Concomitantly, study participants also showed lipopolysaccharide (LPS), endotoxin core antibodies, soluble CD14 (sCD14), and interleukin (IL)-6 in their plasma. Notably, gut epithelial damage, microbial translocation, and systemic inflammation were major events reported in HIV patients in relation to their old age coupled with late HIV treatment. ${ }^{20}$

Interestingly, HIV and age were independently associated with distinct changes in the stool microbiome, with agerelated microbiome changes varying on the HIV serostatus of an individual. In a study involving older HIV seropositive people (median age 61.5 years, $N=14$ ) and seronegative controls (median 58 years, $n=22$ ), the abundances of Allisonella and Anaerovibrio $(p<.0001)$ were higher and $O s$ cillospira $(p=.001)$ and Eggerthella $(p=.047)$ were lower among cases compared with seronegative controls. Consequently, age-related changes in microbiome profile have been shown to be exemplified by Leptotrichiaceae, Escherichia, and Oxalobacter and the genera Butyricimonus has been shown to be significantly increased with age in HIV patients but lower with age in control groups. ${ }^{21}$ Major findings in gut microbiota alteration are shown in Table 2.

\section{Alpha and Beta Diversity}

Several studies have reported HIV-related gut microbiota diversity by using alpha $(\alpha)$ and beta $(\beta)$ diversity indicators. Alpha diversity measures species richness and evenness within samples by using different measures, such as observed species, the Shannon diversity, and the Chao1 index. ${ }^{22,23}$ A study from Marseilles in France revealed that significant diversity changes occurred during HIV infection. The $\alpha$ diversity was significantly reduced in HIV individuals compared with controls as assessed by the Shannon index ${ }^{13}$; however, the study by Zhou et al. showed that the $\alpha$-diversity of fecal microbiota was markedly reduced compared with healthy controls and this is termed dysbiosis and is characterized by low mean counts of prevotella and Bacteroides vulgatus. ${ }^{24}$ A prospective cohort study revealed that baseline $\mathrm{CD}^{+} \mathrm{T}$ cell counts were closely associated with $\alpha$ diversity indices of the intestinal microbiota in HIV patients. Besides, in subgroup comparisons, significantly lower $\alpha$ diversity indices were observed in subjects with $\mathrm{CD} 4^{+} \mathrm{T}$ cell counts $<300 / \mathrm{mm}^{3}$. However, in this group, the increase in $\alpha$ diversity indices was significant after combination antiretroviral therapy (ART) for 15 months. On the other hand, in subjects with $\mathrm{CD}^{+} \mathrm{T}$ cell counts $>300 / \mathrm{mm}^{3}$ and at baseline, the $\alpha$ diversity of the gut microbiota was slightly decreased. ${ }^{25}$ On the contrary, a study on alterations involving $\alpha$ diversity using Shannon and Simpson indices in the fecal microbiota of HIV patients showed no significant difference among cases and controls, despite the higher Shannon index and lower Simpson index in patients with HIV. ${ }^{26}$

Moreover, the $\beta$ diversity, an analysis of inter-individual variability within the samples of study groups, ${ }^{27}$ showed substantial difference in the microbiota of HIV patients from healthy individuals using principal component analysis and principal co-ordinate analysis. ${ }^{24}$ In a study on the gut microbiota profile among HIV patients with diverse immune recovery profiles and in the relationship between the altered bacteria and markers of immune dysfunction, using unweighted UniFrac distance metric $(p<.05)$, and $\beta$ diversity indicated a significant change in the microbial composition among the groups. Enrichment of gut-derived Fusobacterium was associated with suboptimal immune recovery in HIV patients. ${ }^{28}$ However, Ling et al. reported, in HIV-treated and -untreated groups by the unweighted UniFrac analysis, that the diversity of fecal microbiota in HIV patients was unaltered. $^{26}$ This might suggest the magnitude and level of significance of HIV infection compared with its treatment regarding alteration of the gut microbiota diversity. Further, one could also speculate on ART having general and yet microbial population-level effects compared with HIV infection-mediated immune response effects on the microbial diversity.

Further, $\beta$ diversity analysis among homosexual HIV patients and healthy controls indicated significant differences between bacterial compositions due to HIV infection-driven gut microbiota dysbiosis. ${ }^{11}$ A study by Dinh et al. comparing the gut microbiota of HIV patients with healthy controls using pyrosequencing technology revealed significant differences in the community composition of the microbiota assessed by $\beta$ diversity $(p<.05)$ measures. ${ }^{14}$

\section{Inflammation and Translocation Markers}

Persistent immune activation is one of the main predictors of HIV disease progression. ${ }^{26}$ This can be explained by the fact that the gut microbiota is essential for immune homeostasis; so disruptions in intestinal immunity can precipitate gut dysbiosis, which may create an opportunity to induce chronic inflammation in the mucosa and periphery. ${ }^{29}$ Moreover, the microbial diversity was shown to be compromised in HIV infection and this is associated with immune dysfunction and chronic inflammation. ${ }^{30}$ As a fact of advanced disease and AIDS that are associated with immunodeficiency, which can result in opportunistic infections and alterations in the microbiome, ${ }^{31}$ inflammation, immune activation, and opportunistic infection in HIV patients remain as common clinical problems, which is in spite of the available ART. ${ }^{5}$

A cross-sectional study on butyrate-producing bacterial (BPB) species in colonic biopsies and stool involved 18 untreated chronic HIV patients and 14 uninfected as a control. In this study, it was identified that colonic mucosal BPB species were lower in abundance among untreated HIV patients compared with controls. In untreated groups, the abundance of Roseburia intestinalis, a dominant BPB, was decreased. It is known that the relative abundance of $R$. intestinalis is inversely correlated with levels of plasma LPS and SCD14-indicators of microbiota translocation and monocyte activation - as well as with plasma tumor necrosis factor alpha (TNF- $\alpha$ ) and IL-10 levels, which are known as 
Table 2. Alteration of Gut Microbiota Among HiV Patients

\begin{tabular}{|c|c|c|c|}
\hline Author ${ }^{\text {ref. }}$ & Method & Type of specimen & Major finding \\
\hline Cook et al..$^{3}$ & $\begin{array}{l}\text { 16S rRNA } \\
\text { sequencing }\end{array}$ & $\begin{array}{l}\text { Rectal swab and } \\
\text { blood sample }\end{array}$ & $\begin{array}{l}\text { In HIV patients with RNA }<20 \text { copies/mL Campylobacter } \\
\text { Parasutterella and Brachyspira bacteria depleted. HIV patients } \\
\text { with RNA } \leq 200 \text { copies/mL group had shown depletions in } \\
\text { Barnesiella, Helicobacter, and Brachyspira compared with control } \\
\text { groups. Alloprevotell and Pophyromonas were higher in HIV } \\
\text { patients with RNA } \geq 200 \mathrm{~mL} \text { copies group. }\end{array}$ \\
\hline $\begin{array}{l}\text { Villar-Garcia } \\
\text { et al. }{ }^{10}\end{array}$ & $\begin{array}{l}\text { 16S rRNA } \\
\text { sequencing }\end{array}$ & $\begin{array}{l}\text { Stool and blood } \\
\text { sample }\end{array}$ & $\begin{array}{l}\text { Clostridia, Proteobacteria, and Lachnospiraceae were of higher } \\
\text { proportions in the INR than the IR group. }\end{array}$ \\
\hline Lu et $a l .{ }^{11}$ & Flow cytometry & $\begin{array}{l}\text { Stool and blood } \\
\text { sample }\end{array}$ & $\begin{array}{l}\text { Increased Preovtella copri and Prevotella stercorea in the VU group. } \\
\text { A lower abundance of Faecalibacterium prausnitzii and } \\
\text { Haemophilus parainfluenzae was observed in IR and INR groups } \\
\text { compared with the VU group (FDR <0.3). }\end{array}$ \\
\hline Dinh et al. ${ }^{14}$ & $\begin{array}{l}\text { 16S rRNA } \\
\text { sequencing }\end{array}$ & $\begin{array}{l}\text { Stool and blood } \\
\text { sample }\end{array}$ & $\begin{array}{l}\text { Enterobacteriales and Enterobacteriaceae were enriched in cases. } \\
\text { Rikenellaceae and Alistipes were depleted in cases whereas they } \\
\text { were enriched in controls. }\end{array}$ \\
\hline $\begin{array}{l}\text { Machiavelli } \\
\text { et al. }\end{array}$ & $\begin{array}{l}\text { 16S rRNA } \\
\text { sequencing }\end{array}$ & $\begin{array}{l}\text { Stool and blood } \\
\text { sample }\end{array}$ & Prevotellaceae and Paraprevotellaceae increased in HIV patients. \\
\hline Liu et $a .^{21}$ & $\begin{array}{l}\text { 16S rRNA } \\
\text { sequencing }\end{array}$ & $\begin{array}{l}\text { Stool and blood } \\
\text { sample }\end{array}$ & $\begin{array}{l}\text { Abundances of Allisonella and Anaerovibrio }(p<.0001) \text { were higher } \\
\text { and Oscillospira }(p=.001) \text { and Eggerthella }(p=.047) \text { were lower } \\
\text { in cases compared with controls. }\end{array}$ \\
\hline Ling et $a l^{26}$ & 454 & $\begin{array}{l}\text { Pyrosequencing } \\
\text { Faecalibacterium } \\
\text { and }\end{array}$ & $\begin{array}{l}\text { Fecal } \\
\text { Erysipelotrichaceae incertaesedis siginificantly increased and } \\
\text { Clostridium and Barnesiela decreased in HIV patients whereas } \\
\text { Bacteroidete were increased in uninfected controls. }\end{array}$ \\
\hline Lee et $a l^{28}$ & $\begin{array}{l}\text { 16S rRNA } \\
\text { sequencing }\end{array}$ & $\begin{array}{l}\text { Rectal swabs and } \\
\quad \text { blood }\end{array}$ & $\begin{array}{l}\text { Fusobacterium was significantly enriched, and the family } \\
\text { Corynebacteriaceae and its genus Corynebacterium order } \\
\text { Lactobacillales were depleted in the sIR. An increase in the } \\
\text { abundance of the family Veilonellaceae and a depletion of the } \\
\text { genus Eubacterium in HIV patients were observed. }\end{array}$ \\
\hline $\begin{array}{l}\text { Dillon } \\
\quad \text { et } a l .\end{array}$ & $\begin{array}{l}\text { 16S rRNA } \\
\text { sequencing }\end{array}$ & $\begin{array}{l}\text { Colonic biopsies } \\
\text { and stool, blood }\end{array}$ & $\begin{array}{l}\text { The RA of BPB species was significantly lower in the colonic mucosa } \\
\text { of HIV patients relative to controls }(p=.009) \text {. Roseburia } \\
\text { intestinalis }(p=.06) \text { decreased in HIV patients. }\end{array}$ \\
\hline $\begin{array}{l}\text { Rhoades } \\
\text { et al. }{ }^{33}\end{array}$ & $16 \mathrm{~S}$ rRNA & $\begin{array}{l}\text { Blood sample, a } \\
\text { rectal swab }\end{array}$ & $\begin{array}{l}\text { The HIV patients' guts were enriched in Garnerella, Snethia, } \\
\text { Fusobacterium, Lactobacillus, and Helicobater. HIV-negative } \\
\text { individuals had a significantly higher relative abundance of } \\
\text { Oxalobacteria, Streptococcus, Enhydrobacter, Eggerthella, and } \\
\text { Clostridiaceae 02d06. }\end{array}$ \\
\hline
\end{tabular}

16S rRNA, 16S ribosomal ribonucleic acid; FDR, false discovery rate.

inflammation markers. ${ }^{32}$ Dinh et al. examined possible correlations between the relative abundance of taxa and markers of microbial translocation and systemic inflammation, and they reported significant positive correlations between the relative abundance of both Enterobacteriales and Enterobacteriaceae and SCD14 levels $(p<.01){ }^{14}$

The microbiota has impact on shaping the development of the gut immune system whereas its alteration is closely associated with immune dysfunction in HIV patients. Increased immune activation and inflammation are characteristics of HIV infection. Nonetheless, studies on the concentration of plasmatic inflammatory cytokines and LPS binding protein (LBP) demonstrated no significant differences among HIV patients and uninfected, HIV patients showed increased sCD14 plasma levels when compared with uninfected groups $(p=.02){ }^{15}$

Gut microbiota is related to the translocation marker and systemic immune inflammation. A study from Zhejiang, China, revealed that the systemic inflammatory cytokines, such as TNF- $\alpha$, interferon gamma (IFN- $\gamma$ ), and IL-6, were correlated with the abundance of genera Phascolarctobacterium $(p=.014)$, Megamonas $(p=.006)$, Dialister, and Clostridium XIVb, except for Prevotella. For prevalent genera in the healthy controls, Dialister was positively correlated with IL-22 $(p=.000)$ and IFN- $\gamma(R=p=.035)$, and Clostridium XIVb was negatively correlated to IFN- $\gamma(p=.004){ }^{26}$

HIV infection causes impairments in intestinal barriers, which results in an imbalance between aerobic and anaerobic gut microbiota. Dubourg et al. also concluded with dysbiosis in the association between the relative abundance of bacteria families or species (anaerobic and aero tolerant) and levels of biomarkers in HIV patients. The study group revealed that Ruminococcaceae and Faecalbacterium, especially Ruminococcus bromii and $F$. prausnitzii, were inversely correlated with inflammation or immune activation markers when depleted. On the contrary, Enterobacteriaceae and Entrobacteria (especially Escherichia coli and Enterobacter aerogenes) and the Enterococcaceae family (Enterococcus 
faecalis and Enterococcus faecium) were positively correlated with these markers when enriched ${ }^{13}$

Up to date, $\mathrm{CD}^{+} \mathrm{T}$ cell count remains the primary laboratory marker used in the follow-up of disease progression in HIV. ${ }^{29}$ Lee et al. identified that $\mathrm{CD} 4^{+} \mathrm{T}$ cell activation (canonical loading, $\mathrm{CL}=0.923)$ and $\mathrm{CD} 4^{+} \mathrm{T}_{\text {regs }}(\mathrm{CL}=0.639)$ were positively correlated with an increase in the abundance of Fusobacterium $(\mathrm{CL}=0.951)$ but negatively correlated with Lactobacillus $(\mathrm{CL}=0.361)$. In addition, the proportion of naive $\mathrm{CD}^{+}{ }^{\mathrm{T}}$ cells $(\mathrm{CL}=0.509)$ was negatively correlated with $\mathrm{Fu}$ sobacterium $(\mathrm{CL}=-0.951)$ whereas it was positively correlated with the relative abundance of Lactobacillus $(\mathrm{CL}=0.361){ }^{28}$

Moreover, a recent study revealed that old age categories are the prominent factors on inflammation and immune activation markers, which is supported by a recent study. The results show that HIV old aged patients had higher levels of sCD163 $(p=.019), \operatorname{sCD} 14(p=.0006)$, and soluble tumor necrosis factor (sTNF)R2 $(p=.0034)$ compared with uninfected controls. The major differences were noted in patterns of associations of microbiota and inflammatory biomarkers. For example, among HIV patients, Escherichia and Subdoligranulum were positively correlated with sTNFR1 and sTNFR2; whereas Bifidobacterium with TNFR1 and IL-6, and Prevotella inversely correlated with sTNFR1 levels. ${ }^{21}$ Moreover, in the older patient populations ( $\geq 55$ years), recent findings showed that the levels of anti-inflammatory cytokines IL-1RA, T cell cytokine IL-2, and eosinophil maturation factor IL-5 inhibitors were reduced in long-term controlled HIV patients. $^{33}$

\section{Associated Factors Affecting Microbiota in HIV Patients}

A number of studies showed the possible factors associated with alteration of microbiota among HIV patients, and they are presented herein along with a discussion of the two main factors: late diagnosis in old age and ART on the composition and diversity microbiota among HIV patients.

\section{Late diagnosis of HIV in old ages}

According to the United States Centers for Disease Control and Prevention (CDC) report in 2016, 35\% of people aged 50 and older received a diagnosis late in the course of the infection. ${ }^{34}$ The late diagnosis in HIV can affect the immunological, virological, and clinical status of patients. In such a condition, management of patients is challenging and carries a less favorable outcome. ${ }^{35}$ In a study done in India, the majority, 21 $(47.7 \%)$ of deaths were reported within 3 months of starting ART. $^{36}$ In Ethiopia, patients who started ART after they developed AIDS-related illness were 1.4-11.2 times more likely to die than patients who started as early as WHO stage I or II. ${ }^{37}$ Moreover, a study by Luma et al. showed mortality and opportunistic infections to remain significantly higher in lately diagnosed patients. ${ }^{38}$ Older HIV patients, defined as HIVinfected individuals aged 50 years and older, carry the higher risk of late diagnosis, for example, a prospective multicenter cohort study in older HIV-infected people was able to show that $965(68.2 \%)$ patients were diagnosed at age 50 or older. ${ }^{39,40}$

The incidence of infection and noninfectious comorbidity is also higher in HIV-infected people compared with HIVnegative groups, where the duration from infection to diagnosis in $\mathrm{HIV}$ is a strong predictor. ${ }^{41}$ In addition, late presentation for
HIV diagnosis exhibits an increased risk for age-related noninfectious comorbidity and multiple morbidity compared with individuals with early presentation for HIV diagnosis and matched HIV-negative individuals. This is also relevant in patients older than the age of 50 years. ${ }^{42}$ In this regard, a retrospective cohort study revealed that HIV-positive older patients were more likely to have hepatitis $\mathrm{C}$ coinfection $(p=.001)$, hypertension $(p<.001)$, diabetes mellitus $(p<.001)$, higher hepatitis B concentration $(p=.008)$, and higher serum creatinine $(p<.001)$ compared with young HIV-positive patients. ${ }^{43}$ Asher et al. demonstrated that the older patients had a higher mortality rate $(21 \%$ vs. $3.5 \% ; p<.001)$, lower $\mathrm{CD}^{+}$cell counts $(381-228$ vs. 483-261 cells $/ \mathrm{mL} ; p<0.001)$, higher viral load above 100,000 copies/mL, and higher AIDS-defining illness compared with younger patients at the time of diagnosis. ${ }^{35}$

In old age, the manifestation of age-related chronic inflammation and dysregulated immune activation are reflected as primary evidence and constitute an expected mechanism of immunosenescence (a biological phenomenon of gradual deterioration of the immune system occurring in elderly individuals). ${ }^{44}$ Different scholars reported that old age population groups have decreased intestinal function compared with younger age groups. As a result, digestion, nutrient absorption, and immune activity are impaired. ${ }^{45}$ In addition, aging has been associated with decreased production of IL-2 and its receptors, which results in compromised $\mathrm{T}$ cell functionality, reduced memory $\mathrm{T}$ cell population with an underlining reason of reduced $\mathrm{CD}^{+} \mathrm{T}$ cells response in elderly patients to be a result of involution of the thymus gland with decreased productivity. ${ }^{35}$ Apart from aging, changes in the composition of gut microbiota of the old age population could be associated with the decline of the general state of health with malnutrition and an increased need for medication, such as antibiotics and nonsteroidal anti-inflammatory drugs. ${ }^{46}$

Immunologically, older ages manifest as elevated serum levels of neopterin, C-reactive protein (CRP), IL-6, sTNFR-1, and sTNFR-2, which are associated with frailty, disability, and mortality. ${ }^{16}$ The immune system at the time of HIV diagnosis was also shown to be significantly impaired in older patients, with $31 \%$ of older patients tested having a CD $4^{+}$cell count of less than 50 cells $/ \mu \mathrm{L}$ compared with $15 \%$ of younger patients. ${ }^{35} \mathrm{In}$ $\mathrm{HIV}$, infection through direct immune activation in both innate and adaptive immunologic pathways was considered responsible for accelerated immunosenescenc. ${ }^{41,47}$ The main target cell categories in HIV infection were shown to be $\mathrm{CD} 4^{+}$, dendritic cells, monocytes/macrophages, thymocytes, and microglial cells. ${ }^{44}$

As shown in Figure 1, change in the composition of gut microbiota is affected due to multitude of factors including old age, HIV infection, late HIV diagnosis, ART and poor immune prognosis. ${ }^{33,48}$ This could be due to the loss of crucial immune cells because of HIV infection and changes in the composition of microbial communities, for example, the mouth colonizing genera Fusobacteria, Lactobacillus, and multiple Bifidobacteriales were present in gut microbial communities among long-term controlled HIV patients. ${ }^{33}$

\section{$A R T$ and gut microbiota}

Antiretroviral drug discovery and development for treatment of HIV infection has led to fewer AIDS-related complications and better prognosis for HIV-infected people. ${ }^{49}$ However, ART is shown to affect gut microbiota diversity and 


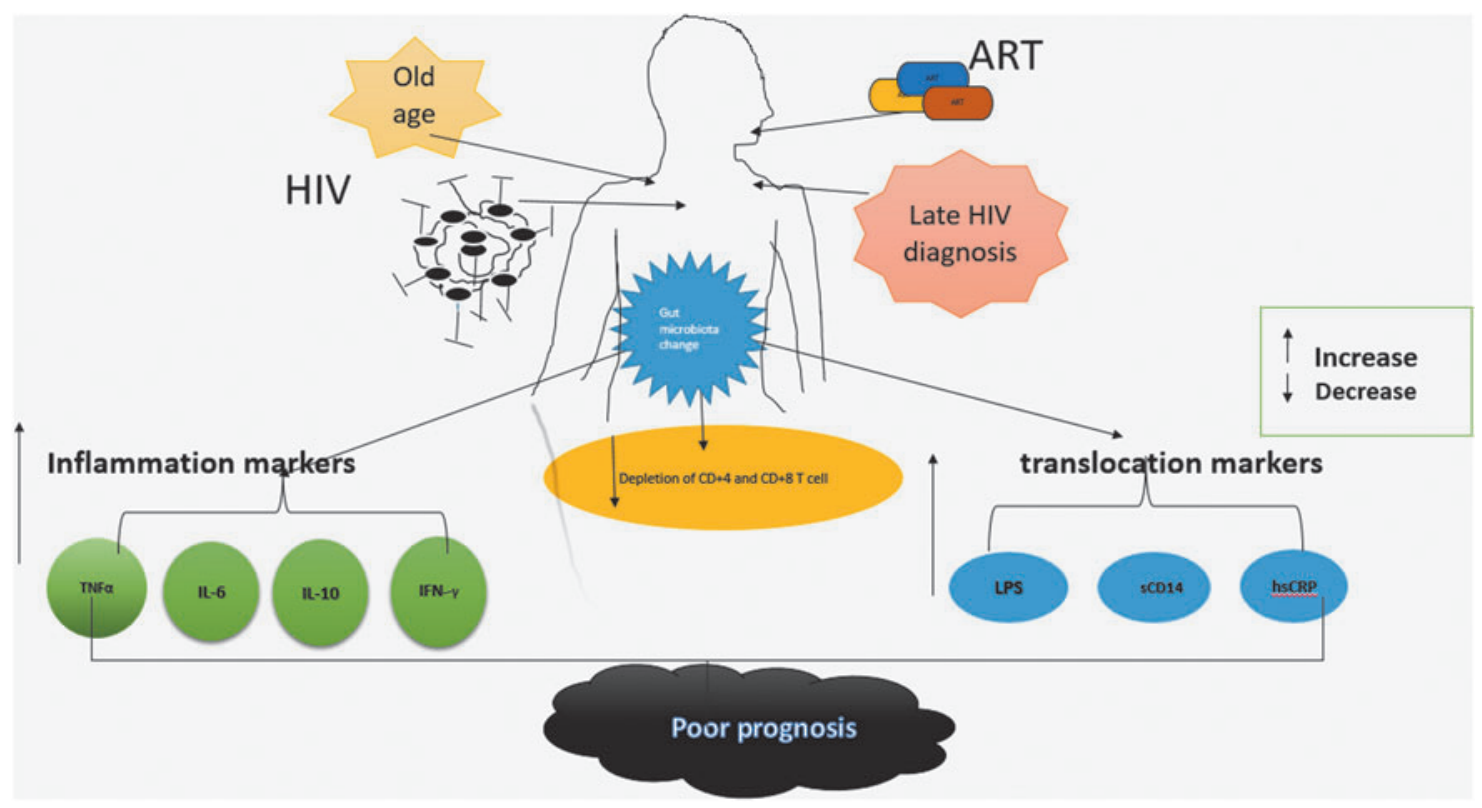

FIG. 1. HIV infection weakens the wall of the intestine and this could create opportunities for bacteria, bacterial toxins, and small molecules to enter into the bloodstream, which may cause systemic inflammation. In addition, HIV damages the GALT and causes depletion of T cells $\left(\mathrm{CD}^{+}\right.$and $\left.\mathrm{CD}^{+}\right)$. Although ART affects the gut microbiota diversity, late HIV diagnosis and old age are exacerbating factors for the disturbance of the gut community. Subsequently, translocation of gut microbiota takes place and evidence shows that probiotics and prebiotics have some promising effect on the restoration of gut microbiota as well as in the decrease of inflammation markers and immune cell activation. ART, antiretroviral therapy; $\mathrm{CD}$, cluster of differentiation; GALT, gut-associated lymphoid tissues; HIV, human immunodeficiency virus.

nowadays findings emerge with different views. Very recently, a study has demonstrated that active fraction of microbiota richness decreased in ART-treated patients compared with untreated patients and health controls. ${ }^{50}$ However, current literature on HIV infection and response to ART has been shown to influence the composition of the microbiota. In a cohort of $26 \mathrm{HIV}$ patients including 10 suboptimal immune responders $\left(=\mathrm{CD} 4^{+} \mathrm{T}\right.$-cell $<350$ cells $\left./ \mu \mathrm{L}\right)$ and 16 optimal immune responders $\left(=\mathrm{CD} 4^{+} \mathrm{T}\right.$-cell $>500$ cells $\left./ \mu \mathrm{L}\right)$, after a minimum of 2 years on suppressive ART, suboptimal responders showed a significant increase in the relative abundance of Fusobacteria as compared with optimal responders and uninfected controls. Concomitantly, the study identified several differentially abundant microbial taxa and there was a notable increase in the abundance of the family Veilonellaceae and a depletion of the genus Eubacterium in other HIV

Table 3. General Characteristics of the Included Studies on Probiotics/Prebiotics Effects

\begin{tabular}{|c|c|c|c|c|c|c|}
\hline Author ${ }^{\text {Ref. }}$ & Study design & Year & Sample size & $\begin{array}{l}\text { Age of } \\
\text { participant } \\
\text { (year) }\end{array}$ & Sex & Country \\
\hline $\begin{array}{l}\text { Villar-Garcia } \\
\text { et al. }\end{array}$ & $\begin{array}{l}\text { Double-blinded control } \\
\text { trial study }\end{array}$ & 2017 & $\begin{array}{l}22 \operatorname{IR}\left(>400 \mathrm{CD}^{+}\right) \\
22 \operatorname{INR}\left(<270 \mathrm{CD}^{+}\right)\end{array}$ & $\begin{array}{l}44(37-49)^{\mathrm{a}} \\
52(47-57)^{\mathrm{a}}\end{array}$ & $\begin{array}{l}37 \mathrm{M} \\
7 \mathrm{~F}\end{array}$ & Spain \\
\hline Deusch et al. ${ }^{50}$ & Blinded randomized study & 2018 & $\begin{array}{l}5 \mathrm{VU} \\
7 \mathrm{IR} \\
4 \mathrm{INR} \\
6 \mathrm{HC}\end{array}$ & NA & $\begin{array}{l}5 \mathrm{M} \\
6 \mathrm{M}, 1 \mathrm{~F} \\
4 \mathrm{M} \\
4 \mathrm{M}, 2 \mathrm{~F}\end{array}$ & Spain, Madrid \\
\hline d'Ettorre et al. ${ }^{57}$ & $\begin{array}{l}\text { Longitudinal } \\
\text { nonrandomized pilot } \\
\text { study }\end{array}$ & 2017 & $10 \mathrm{HIV}+$ & $42(22-53)^{b}$ & M & Italy, Rome \\
\hline d'Ettorre et al. ${ }^{61}$ & Longitudinal pilot study & 2015 & $\begin{array}{l}20 \text { (HIV) } \\
11(\mathrm{HC})\end{array}$ & $\begin{array}{l}54(27-72)^{b} \\
43(28-73)^{b}\end{array}$ & $\begin{array}{l}17 \mathrm{M}, 3 \mathrm{~F} \\
4 \mathrm{M}, 7 \mathrm{~F}\end{array}$ & Italy, Rome \\
\hline Scheri et al. ${ }^{62}$ & Pilot study & 2017 & $8 \mathrm{HIV}$ & $42(31-50)^{\mathrm{c}}$ & M & Italy \\
\hline $\begin{array}{l}\text { Serrano-Villar } \\
\quad \text { et al. }\end{array}$ & Blinded randomized study & 2017 & $\begin{array}{l}\mathrm{HIV}+(\mathrm{VU})=12 \\
\mathrm{HIV}(\text { treated })=8 \mathrm{INR} \\
\mathrm{HIV}(\text { treated })=8 \mathrm{IR} \\
\mathrm{HC}=9\end{array}$ & $\begin{array}{l}34(33-35)^{\mathrm{c}} \\
48(41-53)^{\mathrm{c}} \\
40(33-48)^{\mathrm{c}} \\
47(31-60)^{\mathrm{c}}\end{array}$ & $\begin{array}{l}11 \mathrm{M}, 1 \mathrm{~F} \\
8 \mathrm{M} \\
13 \mathrm{M}, 2 \mathrm{~F} \\
6 \mathrm{M}, 3 \mathrm{~F}\end{array}$ & Spain \\
\hline
\end{tabular}

Values are shown as ${ }^{\mathrm{a}} \mathrm{SD},{ }^{\mathrm{b}}$ median (range), ${ }^{\mathrm{c}}$ median (IQR) for age.

$\mathrm{F}$, female; $\mathrm{M}$, male; NA, not available. 
Table 4. Effect of Probiotics/Prebiotics Supplementation on Gut Microbiota Recovery Among HIV Patients

\begin{tabular}{|c|c|c|c|c|c|}
\hline Author Ref. & $\begin{array}{c}\text { Type of } \\
\text { probiotics/prebiotics }\end{array}$ & Duration & Specimen type & Methods & Major finding \\
\hline $\begin{array}{l}\text { Villar- } \\
\text { Garcia } \\
\text { et al. }\end{array}$ & Saccharomyces boulardii & 12 Weeks & $\begin{array}{l}\text { Stool and blood } \\
\text { sample }\end{array}$ & $16 \mathrm{~S}$ rDNA & $\begin{array}{l}\text { After probiotics supplementation, } \\
\text { Clostridiales species level decreased } \\
\text { compared with the control group. }\end{array}$ \\
\hline $\begin{array}{l}\text { Deusch } \\
\quad \text { et al. }\end{array}$ & scGOS/lcFOS/glutamine & 6 Weeks & Stool sample & $\begin{array}{l}\text { Shotgun } \\
\text { proteomics } \\
16 \mathrm{~S} \text { rDNA }\end{array}$ & $\begin{array}{l}\text { Bifido bacteria increased in abundance } \\
\text { in IR and VU (74-fold) patients after } \\
\text { prebiotics intake. }\end{array}$ \\
\hline $\begin{array}{l}\text { d'Ettorre } \\
\quad \text { et al. }\end{array}$ & $\begin{array}{l}\text { High concentration } \\
\text { lyophilized multi- } \\
\text { strain probiotic }\end{array}$ & 6 Months & $\begin{array}{l}\text { Large and small } \\
\text { intestine } \\
\text { biopsy and } \\
\text { blood sample }\end{array}$ & $\begin{array}{l}\text { PCR, RPMI } \\
\text { media }\end{array}$ & $\begin{array}{l}\text { After } 2 \text { months of probiotics } \\
\text { supplementation, Bifido bacteria spp. } \\
\text { increased }(p<.019) \text { and it remained } \\
\text { stable until the end of the study. }\end{array}$ \\
\hline $\begin{array}{l}\text { d'Ettorre } \\
\quad \text { et al. }\end{array}$ & $\begin{array}{l}\text { Dietary supplement with } \\
\text { probiotics }\end{array}$ & 48 Months & Blood sample & $\begin{array}{l}\text { Minus One } \\
\text { method } \\
\text { (FMO) }\end{array}$ & $\begin{array}{l}\text { Translocation markers, elevated } \\
\text { hsCRP }(45 \%-20 \%) \text {, and the } \\
\text { percentage of CD } 4^{+} \text {CD } 38^{+} \text {HLA- } \\
\text { DR }^{+} \text {T cell }(p<.001) \text { show a } \\
\text { significant reduction after probiotics } \\
\text { consumption. }\end{array}$ \\
\hline $\begin{array}{l}\text { Scheri } \\
\quad \text { et al. }\end{array}$ & $\begin{array}{r}\text { Probiotics preparations } \\
\text { contain live bacteria }\end{array}$ & 6 Months & $\begin{array}{l}\text { Blood and stool } \\
\text { sample }\end{array}$ & $\begin{array}{r}\text { QIAamp } \\
\text { (PCR) }\end{array}$ & $\begin{array}{l}\text { The serum level of } \\
\text { CD } 4^{+} \mathrm{CD} 38^{+} \mathrm{HLA}-\mathrm{DR}{ }^{+} \mathrm{T} \text { cells } \\
\text { shows a statistically significant } \\
\text { reduction at } 6 \text { months compared } \\
\text { with time zero }(p=.008) \text {, and } \\
\text { Bifidobacteria spp. increased in all } \\
\text { patients }(p=.019) \text { after probiotics. }\end{array}$ \\
\hline $\begin{array}{l}\text { Serrano- } \\
\text { Villar } \\
\text { et } a l .^{65}\end{array}$ & scGOS/lcFOS/glutamine & 6 Weeks & Stool sample & $16 \mathrm{~S}$ rRNA & $\begin{array}{l}\text { T cell activation decreased in VU } \\
(p=.006) \text { and INR groups }(p=.04) \\
\text { concomitantly, and microbiota } \\
\text { structure changed in } \beta \text { diversity } \\
\text { analysis after probiotics } \\
\text { intervention. }\end{array}$ \\
\hline
\end{tabular}

FMO, fluorescence minus one method; hsCRP, high sensitivity C-reactive protein; PCR, polymerase chain reaction.

patients. ${ }^{28}$ In a study by Ling et al., alteration in the treatment effect showed a difference in stool microbiota diversity in treated and untreated HIV patients; Firmicutes and Proteobacteria were significantly less abundant in ART-treated patients $(p<.05) .^{26}$

However, in HIV patients after a short-term highly active antiretroviral therapy (HAART), the diversity and composition of fecal microbiota were not shown to be completely restored. ${ }^{13,24,26}$ A cross-sectional study revealed that there was partial restoration of gut microbiota in patients receiving HAART compared with those who did not receive it; levels of Bacteroides, Blautia, and Faecalibacterium displayed a remarkable increase, whereas Roseburia and Rminccoccaceae showed no change. ${ }^{24}$

\section{Probiotics and Prebiotics}

Probiotics commonly refer to viable microorganisms that originated from the gut and they have beneficial health effects on consumers. At a different time, various explanations of probiotics have been given, and several hypotheses were elucidated regarding series of their evolvements with regard to the definition of probiotics. Recently, it has been defined as "live organisms that, when ingested in adequate amounts, exert a health benefit to the host."51-54 Probiotics are able to enrich the human digestive system with good microbes that are able to neutralize the harmful ones and restore the balance between bacteria such as Lactobacilli, Streptococci, Clostridia, Coliform, and Bacteroides. ${ }^{55}$ It has been shown that after 6 months of probiotics supplementation, there was a significant increase in specific bacteria genera compared with the baseline $(p<.05) .{ }^{56}$ Similarly, a study by d'Ettorre et al. revealed that there was a significant increase in Bifidobactria spp. $(p<.019)$ after probiotic intervention. ${ }^{57}$ It also exerts beneficial effects in old age patients. ${ }^{46,58-60}$ Thus, probiotic administration might also promote the reversing of gut damage in HIV-1 infection. ${ }^{54}$

Moreover, as revealed by four earlier studies, there were changes in $\mathrm{T}$ cell activation, that is, the frequencies of $\mathrm{CD}^{+}$ cells simultaneously expressing HLA-DR and CD38 significantly decreased after supplementation with probiotics. ${ }^{55,57,61,62}$ Thus, probiotics may confer a health benefit on the host by the modulation of the immune system and controlling inflammatory gut disorders. ${ }^{54}$

Likewise, the definition of prebiotics has been discussed and refined several times to accommodate emerging knowledge. ${ }^{53}$ Currently, the prebiotic concept has been expanded, in part, because of a far more in-depth understanding of gut microbiome and sequencing studies, which has improved scientific community knowledge on the composition of the microbiota and enabled identification of additional substances influencing colonization. ${ }^{53,63}$ Recently, in 2017 , academic experts in the field of prebiotic research reached a consensus on the 
definition of prebiotics to mean a substrate that is selectively utilized by host microorganisms conferring a health benefit. ${ }^{63}$

In humans, providing probiotics and prebiotics shows promising outcomes to maintaining and restoring the homeostasis of the gut microbial ecosystem. Given this, a recent study has revealed that in frail elderly groups, the Ruminococcaceae (Clostridium cluster IV), Parabacteroides, and Phascolarctobacterium were increased after prebiotic supplementation. ${ }^{51,64}$ Likewise, prebiotics and glutamine have also been shown to exert benefits on gut microbiota and the enterocyte barrier function. Further, they ameliorated HIVassociated dysbiosis and improved innate and adaptive immunity. Indeed, in untreated HIV patients, the nutritional supplement increased the abundance of the depleted Faecalibacterium and Firmicutes (Catenibacterium, Blautia, Eubacterium) and Actinobacteria (Collinsella and Corinebacterium) phyla and it was not observed among ARTtreated patients ${ }^{65}$ The studies discussed in this review deal with the effect of prebiotics and probiotics and this is shown in Tables 3 and 4.

\section{Conclusion}

It summary, the studies show that HIV infection certainly leads to alterations in gut microbiota and a worsening of patients' quality of life. Late diagnosis of HIV in old age has unpleasant outcomes and severe consequences because of immunological alterations due to the double effect of aging and HIV infection on gut microbiota. Hence, the early diagnosis of HIV plays an important role in the management of HIV-related complications. Notably, studies on the late initiation of ART and old age are seen to contribute toward such changes. The reversal of gut microbiota alterations with probiotics and prebiotics can be a promising therapeutic approach. However, further prospective studies are strongly recommended to determine the real association between old age and the late diagnosis of HIV and ART on the alteration of gut microbiota.

\section{Authors' Contributions}

All authors have contributed to this article equally. Conceptualization: A.A.A., Y.-G.F., R.-X.L., D.-Q.Y., B.-Z.L., H.F.P., and T.A.L. Data curation: A.A.A., Y.-G.F., and R.-X.L. Fund acquisition: Y.-G.F., D.-Q.Y. Investigation: A.A.A., Y.-G.F., R.-X.L., and T.A.L. Method: A.A.A., Y.-G.F., D.-Q.Y., B.-Z.L., and T.A.L. Project administration: D.-Q.Y., Y.-G.F. Software: A.A.A., Y.-G.F., and R.-X.L. Writing original draft: A.A.A., Y.-G.F., and D.-Q.Y; Writing review and editing: A.A.A., Y.-G.F., D.-Q.Y., B.-Z.L., and T.A.L.

\section{Acknowledgments}

The authors thank all the authors who placed their findings online as well as those who provided data after personal communication.

\section{Author Disclosure Statement}

The authors declare that they have no competing interests.

\section{Funding Information}

This project was supported by the Natural Science Fund of Anhui Province (1608085MH174) and the program of technical support for Liuzhou (2019WT020089), which was authorized by the Chinese National Center for AIDS/STD Control and Prevention.

\section{References}

1. UNAIDS data 2018. Available at www.unaids.org/en/ resources/documents/2018/unaids-data-2018 accessed on February 16, 2019.

2. Storm-Larsen C, Stiksrud B, Eriksen C, et al.: Microbial translocation revisited: Targeting the endotoxic potential of gut microbes in HIV-infected individuals. AIDS 2019;33: 645-653.

3. Cook RR, Fulcher JA, Tobin NH, et al:: Effects of HIV viremia on the gastrointestinal microbiome of young MSM. AIDS 2019;33:793-804.

4. Guinane CM, Cotter PD: Role of the gut microbiota in health and chronic gastrointestinal disease: Understanding a hidden metabolic organ. Therap Adv Gastroenterol 2013;6: 295-308.

5. Samuelson DR, Charles TP, de la Rua NM, et al.: Analysis of the intestinal microbial community and inferred functional capacities during the host response to Pneumocystis pneumonia. Exp Lung Res 2016-;42:425-439.

6. El-Far M, Tremblay CL: Gut microbial diversity in HIV infection post combined antiretroviral therapy: A key target for prevention of cardiovascular disease. Curr Opin HIV AIDS 2018;13:38-44.

7. Sessa L, Reddel S, Manno E, et al.: Distinct gut microbiota profile in ART-treated perinatally HIV-infected patients associated with cardiac and inflammatory biomarkers. AIDS 2019;33:1001-1011.

8. Huang Y, Luo D: Changes and determinants of healthrelated quality of life among people newly diagnosed with HIV in China: A 1-year follow-up study. Qual Life Res 2019;28:35-46.

9. Singh V, Roth S: Microbiota dysbiosis controls the neuroinflammatory response after stroke. J Neurosci 2016;36: 7428-7440.

10. Villar-Garcia J, Guerri-Fernandez R, Moya A, et al: Impact of probiotic Saccharomyces boulardii on the gut microbiome composition in HIV-treated patients: A double-blind, randomised, placebo-controlled trial. PloS One 2017;12:e0173802.

11. Lu W, Feng Y, Jing F, et al.: Association between gut microbiota and $\mathrm{CD} 4^{+}$recovery in HIV-1 infected patients. Front Microbiol 2018;9:1451,

12. Phelan JA, Abrams WR, Norman RG, et al:: Design aspects of a case-control clinical investigation of the effect of HIV on oral and gastrointestinal soluble innate factors and microbes. PloS One 2014;9:e112901.

13. Dubourg G, Lagier JC, Hüe S, et al:: Gut microbiota associated with HIV infection is significantly enriched in bacteria tolerant to oxygen. BMJ Open Gastroenterol 2016;3:e000080.

14. Dinh DM, Volpe GE, Duffalo C, et al.: Intestinal microbiota, microbial translocation, and systemic inflammation in chronic HIV infection. J Infect Dis 2015;211:19-27.

15. Machiavelli A, Duarte RTD, Pires MMS, Zárate-Bladés CR, Pinto AR: The impact of in utero HIV exposure on gut microbiota, inflammation, and microbial translocation. Gut Microbes 2019;10:599-614.

16. Jones L, Kumar J, Mistry A, Sankar Chittoor Mana T, Perry G, Reddy VP, Obrenovich M: The Transformative Possibilities of the Microbiota and Mycobiota for Health, Disease, Aging, and Technological Innovation. Biomedicines 2019;7:24. 
17. Thevaranjan N, Puchta A, Schulz C, et al.: Age-associated microbial dysbiosis promotes intestinal permeability, systemic inflammation, and macrophage dysfunction. Cell Host Microbe 2017;21:455.e4-466.e4.

18. Obrenovich MEM: Leaky gut, leaky brain? Microorganisms 2018;6:107.

19. Bandera A, De Benedetto I, Bozzi G, Gori A: Altered gut microbiome composition in HIV infection: Causes, effects and potential intervention. Curr Opin HIV AIDS 2018;13: 73-80.

20. Tincati $\mathrm{C}$, Merlini $\mathrm{E}$, Braidotti $\mathrm{P}$, et al.: Impaired gut junctional complexes feature late-treated individuals with suboptimal $\mathrm{CD} 4^{+} \mathrm{T}$-cell recovery upon virologically suppressive combination antiretroviral therapy. AIDS 2016;30: 991-1003.

21. Liu J, Johnson R, Dillon S, et al.: Among older adults, agerelated changes in the stool microbiome differ by HIV-1 serostatus. EbioMedicine 2019;40:583-594.

22. Prehn-Kristensen A, Zimmermann A, Tittmann L, et al.: Reduced microbiome alpha diversity in young patients with ADHD. PloS One 2018;13:e0200728.

23. Jost L: Partitioning diversity into independent alpha and beta components. Ecology 2007;88:2427-2439.

24. Zhou Y, Ou Z, Tang X, et al.: Alterations in the gut microbiota of patients with acquired immune deficiency syndrome. J Cell Mol Med 2018;22:2263-2271.

25. Ji Y, Zhang F, Zhang R, et al.: Changes in intestinal microbiota in HIV-1-infected subjects following cART initiation: Influence of $\mathrm{CD}^{+}{ }^{+} \mathrm{T}$-cell count. Emerg Microbes Infect 2018;7:113.

26. Ling Z, Jin C, Xie T, Cheng Y, Li L, Wu N: Alterations in the fecal microbiota of patients with HIV-1 infection: An observational study in a Chinese population. Sci Rep 2016; 6:30673.

27. Ticinesi A, Milani C: Gut microbiota composition is associated with polypharmacy in elderly hospitalized patients. Sci Rep 2017;7:11102.

28. Lee SC, Chua LL, Yap SH, et al.: Enrichment of gutderived Fusobacterium is associated with suboptimal immune recovery in HIV-infected individuals. Sci Rep 2018; $8: 14277$.

29. Zilberman-Schapira G, Zmora N, Itav S, Bashiardes S, Elinav H, Elinav E: The gut microbiome in human immunodeficiency virus infection. BMC Med 2016;14:83.

30. Pinto-Cardoso S, Klatt NR, Reyes-Teran G: Impact of antiretroviral drugs on the microbiome: Unknown answers to important questions. Curr Opin HIV AIDS 2018;13:53-60.

31. Chehoud C, Stieh DJ, Bailey AG, et al.: Associations of the vaginal microbiota with HIV infection, bacterial vaginosis, and demographic factors. AIDS 2017;31:895-904.

32. Dillon SM, Kibbie J, Lee EJ, et al:: Low abundance of colonic butyrate-producing bacteria in HIV infection is associated with microbial translocation and immune activation. AIDS 2017;31:511-521.

33. Rhoades N, Mendoza N, Jankeel A, et al.: Altered immunity and microbial dysbiosis in aged individuals with long-term controlled HIV infection. Front Immunol 2019;10:463.

34. Centers for Disease Control and Prevention: HIV among people aged 50 and older. Available at www.cdc.gov/hiv/ group/age/olderamericans/index.html (2016), accessed August 10, 2016.

35. Asher I, Guri KM, Elbirt D, et al.: Characteristics and outcome of patients diagnosed with HIV at older age. Medicine 2016;95:e2327.
36. Joseph N, Sinha U, Tiwari N, Ghosh P, Sindhu P: Prognostic factors of mortality among adult patients on antiretroviral therapy in India: A hospital based retrospective cohort study. Biomed Res Int 2019;2019:1419604.

37. Biset Ayalew M: Mortality and its predictors among HIV infected patients taking antiretroviral treatment in Ethiopia: A systematic review. AIDS Res Treat 2017;2017: 5415298.

38. Luma $\mathrm{H}$, Jua $\mathrm{P}$, Donfack $\mathrm{O}$, et al.: Late presentation to HIV/AIDS care at the Douala general hospital, Cameroon: Its associated factors, and consequences. BMC Infect Dis 2018;18:298.

39. Musumari PM, Tangmunkongvorakul A: Socio-behavioral risk factors among older adults living with HIV in Thailand. PloS One 2017;12:e0188088.

40. Hentzien M, Delpierre C, Pugliese P, et al.: Derivation and internal validation of a mortality risk index for aged people living with HIV: The Dat'AIDS score. PloS One 2018;13: $\mathrm{e} 0195725$.

41. Ripa M, Chiappetta S, Tambussi G: Immunosenescence and hurdles in the clinical management of older HIVpatients. Virulence 2017;8:508-528.

42. Guaraldi G, Zona S, Menozzi M, et al.: Late presentation increases risk and costs of non-infectious comorbidities in people with HIV: An Italian cost impact study. AIDS Res Ther 2017;14:8.

43. Sule HM, Agaba PA, Idoko JA, et al.: Treatment outcomes among older human immunodeficiency virus-infected adults in Nigeria. Open Forum Infect Dis 2017;4:ofx031.

44. Shankar EM, Velu V, Kamarulzaman A, Larsson M: Mechanistic insights on immunosenescence and chronic immune activation in HIV-tuberculosis co-infection. World $\mathbf{J}$ Virol 2015;4:17-24.

45. Odamaki $\mathrm{T}$, Kato $\mathrm{K}$, Sugahara $\mathrm{H}$, et al:: Age-related changes in gut microbiota composition from newborn to centenarian: A cross-sectional study. BMC Microbiol 2016; 16:90.

46. Rondanelli M, Giacosa A, Faliva MA, Perna S, Allieri F, Castellazzi AM: Review on microbiota and effectiveness of probiotics use in older. World J Clin Cases 2015;3:156-162.

47. Siedner MJ: Aging, health, and quality of life for older people living with HIV in Sub-Saharan Africa: A review and proposed conceptual framework. J Aging Health 2019; 31:109-138.

48. Choi J, Hur TY, Hong Y: Influence of altered gut microbiota composition on aging and aging-related diseases. J Lifestyle Med 2018;8:1-7.

49. Krishnan S, Schouten JT, Atkinson B, et al:: Changes in metabolic syndrome status after initiation of antiretroviral therapy. J Acquir Immune Defic Syndr 2015;68:73-80.

50. Deusch S, Serrano-Villar S, Rojo D, et al.: Effects of HIV, antiretroviral therapy and prebiotics on the active fraction of the gut microbiota. AIDS 2018;32:1229-1237.

51. Nagpal R, Mainali R, Ahmadi S, et al.: Gut microbiome and aging: Physiological and mechanistic insights. Nutr Healthy Aging 2018;4:267-285.

52. Nazir Y, Hussain SA: Probiotics and their potential preventive and therapeutic role for cancer, high serum cholesterol, and allergic and HIV diseases. Biomed Res Int 2018;2018:3428437.

53. La Fata G, Rastall RA, Lacroix C, Harmsen HJM, Mohajeri MH, Weber P, Steinert RE: Recent Development of Prebiotic Research-Statement from an Expert Workshop. Nutrients 2017;9:1376. 
54. Hill C, Guarner F, Reid G, et al.: Expert consensus document. The International Scientific Association for Probiotics and Prebiotics consensus statement on the scope and appropriate use of the term probiotic. Nat Rev Gastroenterol Hepatol 2014;11:506-514.

55. D'Angelo C, Reale M, Costantini E: Microbiota and Probiotics in Health and HIV Infection. Nutrients 2017;9: 615.

56. Trinchieri V, Laghi L, Vitali B, Parolin C, Giusti I, Capobianco D, Mastromarino P, De Simone C: Efficacy and Safety of a Multistrain Probiotic Formulation Depends from Manufacturing. Front Immunol 2017;8:1474.

57. d'Ettorre G, Rossi G, Scagnolari C, et al.: Probiotic supplementation promotes a reduction in $\mathrm{T}$-cell activation, an increase in Th17 frequencies, and a recovery of intestinal epithelium integrity and mitochondrial morphology in ART-treated HIV-1-positive patients. Immun Inflamm Dis 2017;5:244-260.

58. Lahtinen SJ, Tammela L, Korpela J, et al:: Probiotics modulate the Bifidobacterium microbiota of elderly nursing home residents. Age (Dordr) 2009;31:59-66.

59. Ahmed M, Prasad J, Gill H, Stevenson L, Gopal P: Impact of consumption of different levels of Bifidobacterium lactis HN019 on the intestinal microflora of elderly human subjects. J Nutr Health Aging 2007;11:26-31.

60. Bartosch S, Fite A, Macfarlane GT, McMurdo ME: Characterization of bacterial communities in feces from healthy elderly volunteers and hospitalized elderly patients by using real-time PCR and effects of antibiotic treatment on the fecal microbiota. Appl Environ Microbiol 2004;70:35753581 .

61. d'Ettorre G, Ceccarelli G, Giustini N, et al.: Probiotics reduce inflammation in antiretroviral treated, HIV-infected individuals: Results of the "Probio-HIV" clinical trial. PloS One 2015;10:e0137200.

62. Scheri GC, Fard SN, Schietroma I, et al.: Modulation of tryptophan/serotonin pathway by probiotic supplementation in human immunodeficiency virus-positive patients: Preliminary results of a new study approach. Int J Tryptophan Res 2017;10:1178646917710668.

63. Gibson GR, Hutkins R, Sanders ME, et al.: Expert consensus document: The International Scientific Association for Probiotics and Prebiotics (ISAPP) consensus statement on the definition and scope of prebiotics. Nat Rev Gastroenterol Hepatol 2017;14:491-502.

64. Tran TTT, Cousin FJ, Lynch DB, et al:: Prebiotic supplementation in frail older people affects specific gut microbiota taxa but not global diversity. Microbiome 2019;7:39.

65. Serrano-Villar S, Vazquez-Castellanos JF, Vallejo A, et al.: The effects of prebiotics on microbial dysbiosis, butyrate production and immunity in HIV-infected subjects. Mucosal Immunol 2017;10:1279-1293.

Address correspondence to:

Yin-Guang Fan

Department of Epidemiology and Biostatistics School of Public Health

Anhui Medical University

81 Meishan Road

Hefei 230032

Anhui

China

E-mail: fanyinguang@163.com 